\title{
A Administração é uma Ciência? Reflexões Epistemológicas acerca de sua Cientificidade
}

\author{
Elói Júnior Damke 1 \\ Silvana Anita Walter ${ }^{2}$ \\ Eduardo Damião da Silva ${ }^{3}$
}

\section{Resumo}

Este estudo de caráter epistemológico tem como objetivo expor e discutir a questão da cientificidade da administração. Essa discussão já foi realizada em outros estudos, sem ter sido, contudo, a exemplo deste estudo, efetuado por meio da análise dos critérios epistemológicos dos filósofos Karl Popper, Thomas Kuhn e Imre Lakatos. Com base nas correntes epistemológicas apresentadas, pode-se concluir: que a administração, como teoria do conhecimento, pode ser considerada ciência, o que decorre da possibilidade de falsear os estudos dessa área conforme o falseacionismo sofisticado de Popper; que a administração atende aos pressupostos da ciência paradigmática de Kuhn, apesar de não existir consenso sobre em que etapa se encontra e se adéqua aos moldes dos programas de pesquisa apresentados por Lakatos. Sabe-se que a administração ainda possui um longo caminho a percorrer em busca da ampliação de seu rigor metodológico e de seu amadurecimento, mas desconsiderá-la como ciência, além de não auxiliar neste amadurecimento, acaba por desprestigiar um amplo grupo de atores sociais - as organizações - que não são objeto principal de estudo de outras ciências.

Palavras-chave: Epistemologia. Cientificidade da administração. Karl Popper. Thomas Kuhn. Imre Lakatos.

\section{Introdução}

Levando-se em consideração o incremento no número de pesquisadores dedicados à administração, à ampliação do volume de livros e de traba-

\footnotetext{
${ }^{1}$ Doutorando em Administração pelo Programa de Pós-Graduação da Pontifícia Universidade Católica do Paraná. Endereço: Rua Imaculada Conceição, 1.155. Prado Velho. CEP: 80215-901 - Curitiba, PR-Brasil. E-mail: eloi.damke@gmail.com

${ }^{2}$ Doutoranda em Administração pelo Programa de Pós-Graduação da Pontifícia Universidade Católica do Paraná. Endereço: Rua Imaculada Conceição, 1.155, Bloco Acadêmico, $2^{\circ}$ andar, Sala 217. Prado Velho. CEP: 80215-901 - Curitiba, PR - Brasil. E-mail: silvanaanita.walter@gmail.com

${ }^{3}$ Decano do Centro de Ciências Sociais Aplicadas e Docente do Programa de Pós-Graduação da Pontifícia Universidade Católica do Paraná. Endereço: Rua Imaculada Conceição, 1.155, Bl. Acadêmico. PradoVelho. CEP: 80215-901-Curitiba, PR-Brasil. E-mail: eduardo.damiao@pucpr.br Artigo recebido em: 11/04/2010. Aceito em: 12/08/2010. Membro do Corpo Editorial Científico responsável pelo processo editorial: Gilberto de Oliveira Moritz.
} 
lhos de natureza técnico-científica publicados, bem como ao aumento da oferta de cursos de graduação e pós-graduação stricto sensu em administração, é inegável a relevância dessa área do conhecimento.

No entanto, inúmeras críticas são constantemente direcionadas a essa área, em especial oriundas de filósofos das ciências puras que destacam a falta de critérios de demarcação científica dos trabalhos nas áreas administrativas. Outras críticas se referem à ausência de posições teórico-metodológicas adotadas em pesquisas dessa área.

Nesse contexto, nas últimas décadas, o desenvolvimento e a consolidação da administração como área de conhecimento com características particulares têm levado estudiosos a reflexões sobre sua cientificidade.

Para muitas comunidades acadêmicas organizadas, representadas pelos grupos de cientistas e filósofos da ciência, a administração não pode ser considerada uma ciência, uma vez que "toma emprestado" e aplica conhecimentos de outras ciências, como da Psicologia, da Economia e da Antropologia, dentre outras. Para outras, a administração deve ser considerada uma "arte", uma vez que não pode ser explicada ou pesquisada, além de ser praticada não apenas entre aqueles que possuem formação acadêmica específica, como também por pessoas que não são formadas e contam somente com a prática. Há, ainda, as que defendem que a administração possui cientificidade, devendo ser considerada como uma ciência social aplicada.

Dado o exposto, e por se considerar relevante para essa área discutir sua cientificidade, realizou-se o estudo epistemológico ora apresentado com o objetivo de debater a cientificidade da administração por meio da análise dos critérios epistemológicos dos filósofos Karl Popper, Thomas Kuhn e Imre Lakatos. Buscou-se, assim, responder à seguinte pergunta de pesquisa:

\section{A administração pode ser considerada uma ciência?}

A discussão sobre a cientificidade da administração já foi realizada em outros estudos, como o de Machlup (1994), o de Silva (2002) e o de Augusto e Walter (2008), sem ter sido, contudo, a exemplo deste estudo, efetuado por meio da análise dos critérios epistemológicos dos filósofos Karl Popper, Thomas Kuhn e Imre Lakatos.

Este artigo encontra-se estruturado de forma que realiza, na próxima seção, uma exposição sobre a epistemologia e a ciência e suas contribuições para o embasamento deste estudo; na terceira seção, apresenta os critérios epistemológicos dos filósofos Karl Popper, Thomas Kuhn e Imre Lakatos e as implicações desses critérios para a classificação da administração como ciên- 
cia; e, na quarta seção, exibe as considerações finais a respeito da discussão deste estudo e da caracterização da administração como ciência.

\section{A Epistemologia e a Ciência}

Nesta seção, discutem-se a epistemologia e a ciência, bem como as contribuições delas para este estudo.

\subsection{A Epistemologia e sua Contribuição para os Fundamentos da Teoria Cientificista do Conhecimento}

De acordo com Santos (2004), nenhuma pesquisa pode ser elaborada sem a âncora epistemológica. O fenômeno ou o fato a ser pesquisado requer bases investigativas na literatura do ramo do saber em análise. Leis, teoremas, axiomas, princípios, postulados e outros dão a sustentação necessária à comprovação das hipóteses ou das questões norteadoras da pesquisa.

A epistemologia é, pois, teoria do conhecimento. De acordo com Houaiss (2001), a epistemologia está relacionada à questão da reflexão em torno da natureza e dos limites do conhecimento humano. De acordo com Santos (2004), o termo epistemologia não possui um sentido único, consistindo em um conceito flexível que varia conforme os pressupostos filosóficos e ideológicos dos críticos de diferentes países e culturas.

Dos estudos de Mariguela (1995), Kant (1971), Bachelard (1971), Bombassaro (1994), Zilles (1994), podem-se extrair as seguintes definições para a epistemologia: teoria geral do conhecimento ou gênese e estrutura das ciências; estudo dos princípios, das hipóteses e da aplicação das ciências; estudo metódico e reflexivo do saber, sua organização, sua formação, seu desenvolvimento, seu funcionamento e seus produtos intelectuais; filosofia das ciências; teoria do conhecimento; lógica das ciências; e metaciência.

As definições apresentadas evidenciam que a epistemologia tem, por objeto formal, o estudo crítico-analítico da produção do conhecimento, podendo ser considerada uma matéria interdisciplinar e multirreferencial. A epistemologia também pode ser considerada a história da ciência. De acordo com Lopes e Bernardes (2001), como a ciência é regulada pela busca da verdade, outra condição de ciência se estabelece: o paradigma, que, na vi- 
são dos autores, cumpre a função de estabelecer condições de objetividade ao conhecimento científico. A ciência, sob a ótica dos paradigmas, é mais bem compreendida com base nos escritos de Kuhn (2003).

A partir do apresentado nesta subseção, nota-se que a epistemologia consiste em uma base fundamental para o desenvolvimento de estudos científicos, e sua abordagem torna-se essencial em estudos sobre a cientificidade de uma área de conhecimento.

\subsection{A Ciência e suas Classificações}

Inicia-se esta subseção destacando-se alguns aspectos que conceituam e caracterizam ciência. No entanto, entende-se que o pano de fundo relacionado à ciência e suas classificações é vasto e não é o objetivo principal deste trabalho.

Várias são as definições encontradas para ciência, e a área que se preocupa em responder a essa questão - aparentemente simples, mas extremamente complexa - é a Filosofia da Ciência. Em linhas gerais, a ciência, cuja finalidade principal é ampliar os seus conhecimentos específicos, pode ser entendida como um processo ou uma tentativa de compreensão de uma realidade em particular, o que dificulta a formulação de um conceito genérico da mesma (CORBI, 1998).

De acordo com Lakatos (1979), durante séculos, o conhecimento significou conhecimento provado pela força do intelecto ou pela prova dos sentidos. A sabedoria e a integridade intelectual exigiam que fossem desconsideradas afirmações não provadas, o que minimizou o hiato entre a especulação e o conhecimento estabelecido. Essa era a concepção comum de ciência até então, vestida nas roupagens do positivismo lógico, critério baseado no empirismo justificacionista-indutivista da concepção tradicional de ciência.

Essa concepção acerca da visão de ciência, assim como do desenvolvimento das ciências, foi posta à prova com a física newtoniana. Os resultados obtidos por Einstein causaram mudanças e resultaram no entendimento de que o conhecimento científico não é, necessariamente, conhecimento demonstrado.

Além disso, destaca-se que, nas origens da história da ciência, ela possuía como preocupação principal ampliar os conhecimentos, o que leva à compreensão de que se tratava da ciência formal. Já na atualidade, o proces- 
so evolucionário das ciências as distinguiu em formais e reais (CORBI, 1998; FIGUEIRAS, 1996).

As ciências formais possuem caráter analítico e tratam de objetos ou entidades que não existem na realidade. Já as ciências reais tratam de objetos ou entidades existentes e, portanto, observáveis empiricamente. As ciências reais também são conhecidas como ciências empíricas e experimentais e sofrem uma segunda divisão: ciências naturais e ciências sociais. A primeira trata de conhecer as leis da natureza, e a segunda, em particular, o comportamento humano. Ademais, as ciências naturais e as sociais, por sua vez, se subdividem em ciência pura, que é aquela que se interessa basicamente por conhecimentos, e ciências aplicadas que tratam de modificar e/ou configurar a realidade.

No que tange à administração, ela pode ser considerada uma ciência social (WHITLEY, 1977), isto que seu objeto de estudo se constitui de fenômenos de ordem social, ou seja, do estudo e da melhoria da coordenação e do controle de atividades humanas associadas. Além disso, a administração também pode ser classificada como uma ciência aplicada (THOMSON, 1956), ou seja, uma ciência social aplicada.

Augusto e Walter (2008) argumentam que a dificuldade de a administração ser considerada uma ciência pela academia se deve exatamente ao fato de consistir em uma ciência social. Isso porque as ciências sociais possuem um objeto de estudo mais complexo, o que impossibilita que atinjam critérios de cientificidade baseados nas ciências naturais, como a neutralidade e a objetividade. A esse respeito, Augusto e Walter (2008) destacam que não deveriam ser empregados critérios das ciências naturais para avaliar a cientificidade de uma ciência social como a administração. Assim, esses pesquisadores defendem que a administração pode ser considerada uma ciência e que deveria se preocupar com os critérios de cientificidade que realmente podem ser aplicados a ela ou seja, com a relevância e a validade dos resultados obtidos por meio do rigor metodológico.

Diante das diferentes concepções e divergências sobre o conceito de ciência, empregam-se, neste estudo, as ideias dos filósofos Kuhn, Popper e Lakatos acerca do que é conhecimento científico e de sua natureza. 


\section{Os Critérios Epistemológicos de Popper, de Kuhn e de Lakatos}

Nesta seção, exibem-se os critérios epistemológicos dos filósofos Karl Popper, Thomas Kuhn e Imre Lakatos, e as implicações desses critérios para a classificação da administração como ciência.

\subsection{A Ciência de Karl Popper - O Falseacionismo}

Karl Popper, austríaco naturalizado britânico, é considerado o pai do racionalismo crítico, além de ser conhecido por muitos como um dos filósofos mais influentes da ciência contemporânea.

Para discutir a inserção de Popper e de suas considerações na Filosofia da Ciência, é relevante discutir a historicidade da ciência. Para tal, faz-se uma breve exposição das objeções à visão comum da ciência, examinando a questão da indução.

O indutivismo pode ser considerado ciência cujo conhecimento deriva dos dados da experiência e uma concepção de senso comum da ciência atualmente aceita. Para os indutivistas, a ciência começa com a observação (CHALMERS, 1993) que fornece uma base segura sobre qual conhecimento científico pode ser construído. Além disso, o conhecimento científico é obtido a partir de proposições de observação por indução.

Para explicar no que consiste a indução, recorre-se a Chalmers (1993), o autor salienta que a indução é um tipo de raciocínio que nos leva de uma lista finita de afirmações singulares para uma afirmação universal, ou seja, leva-nos do particular para o todo, e que esse tipo de raciocínio é denominado raciocínio indutivo.

Basicamente, o indutivista constrói conhecimento científico a partir de bases fornecidas pela observação e pela experiência. Chalmers (1993, p. 37) exemplifica o indutivismo da seguinte forma:

"1 Todos os livros de filosofia são chatos.

2 Este livro é um livro de filosofia.

3 Este livro é chato".

Nesse exemplo de critério indutivo, (1) e (2) são premissas e (3) é a conclusão. Está explícito que, se (1) e (2) são verdadeiras, então (3) é verdadeira. Não é possível (3) ser falsa, uma vez que é dado que (1) e (2) são 
verdadeiras. Se (1) e (2) fossem verdadeiras e (3) fosse falsa, ocorreria uma contradição. Essa é a característica-chave de uma dedução logicamente válida. Se as premissas de uma dedução logicamente válida são verdadeiras, então a conclusão deve ser verdadeira. No entanto, Chalmers (1993, p. 37) utiliza-se de uma ligeira modificação nas premissas de uma dedução não válida.

"1. Muitos livros de filosofia são chatos.

2. Este livro é um livro de filosofia.

3. Este livro é chato".

Nesta situação, (3) não segue necessariamente (1) e (2). É possível (1) e (2) serem verdadeiras e, ainda assim, (3) ser falsa. Mesmo que (1) e (2) sejam verdadeiras, não se pode afirmar que (3) seja verdadeira, uma vez que uma minoria de livros de filosofia não são chatos. Assegurar que (1) e (2) são verdadeiras e (3) como falsa não envolve uma contradição. Portanto, o argumento é inválido.

Esse exemplo simplista é empregado por Chalmers (1993) para evidenciar o problema da indução. Tudo o que a lógica pode oferecer é que se as premissas são verdadeiras, então a conclusão deve ser verdadeira. Mas se as premissas são ou não verdadeiras, é uma questão que não pode ser resolvida com recurso restrito pura e simplesmente à lógica. Nesse sentido, o princípio da indução pode não ser justificado.

No entanto, os indutivistas ingênuos, segundo Chalmers (1993), na tentativa de enfrentar essas críticas, recuam para a "probabilidade" no sentido de defesa própria. Em específico, outro exemplo se faz importante para aclarar essa tendência indutivista. Em um sentido intuitivo, não técnico de "provável", se pode estar preparado para afirmar que é provável, até certo grau, que um fumante inveterado morrerá de câncer de pulmão. Essa premissa apoia-se em dados estatísticos disponíveis. Existe, sim, uma conexão causal entre as duas variáveis - tabagismo e câncer de pulmão -, mas essa variável não pode ser afirmada na sua totalidade apenas com base nessa probabilidade. Assim, no caso desse exemplo, pelo fato de não se poder utilizar a possibilidade de justificação lógica, resta, segundo os pressupostos empiristas dos próprios defensores dessa concepção, unicamente a justificação empírica. No entanto, os filósofos John Locke e David Hume apontaram, nos Séculos XVII e XVIII, que a justificação empírica da indução envolve dificuldades insuperáveis.

Os exemplos mencionados, em sua simplicidade, não são suficientes para assegurar a invalidade do processo indutivo, mas são um esforço para ilustrar o problema da indução. Dada uma proposição geral qualquer, não 
importa quão numerosas e variadas tenham sido as observações que a ela forneceram suporte indutivo, é sempre possível que a próxima observação contrarie as anteriores, falseando a proposição geral.

Popper faz objeções incisivas à concepção comum de ciência (indutivista) no livro Logik der Forschung, publicado em Viena. A ideia central de Popper é a de substituir o empirismo justificacionista-indutivista da concepção tradicional por um empirismo não justificacionista e não indutivista, que ficou conhecido por falseacionismo (CHIBENI, 2004).

Popper rejeita que as teorias científicas sejam construídas por um processo indutivo a partir de uma base empírica neutra e propõe que elas têm um caráter eminentemente conjetural. "Teorias são criações livres da mente, destinadas a ajustar-se tão bem quanto possível ao conjunto de fenômenos de que tratam" (POPPER, 1975, p. 76). Na visão desse filósofo, uma vez proposta, uma teoria deve ser rigorosamente testada por observações e por experimentos. Se falhar, deve ser sumariamente eliminada e substituída por outra capaz de passar nos testes em que a anterior falhou, bem como em todos aqueles nos quais tenha passado. Assim, a ciência avança por um processo de tentativa e de erro, de conjeturas e de refutações.

A cientificidade de uma teoria reside não em sua impossível prova a partir de uma base empírica, mas em sua refutabilidade. Resumidamente, Popper rejeita que a ciência se desenvolva por acumulação e considera que a ciência progride por meio de um processo revolucionário pelo qual uma teoria mais antiga é rejeitada e substituída por uma nova teoria, incompatível com a anterior.

$\mathrm{O}$ argumento de Popper acerca do caráter do raciocínio lógico e dedutivo e o argumento indutivista de Hume são representados, respectivamente, no lado direito e esquerdo da Figura 1.

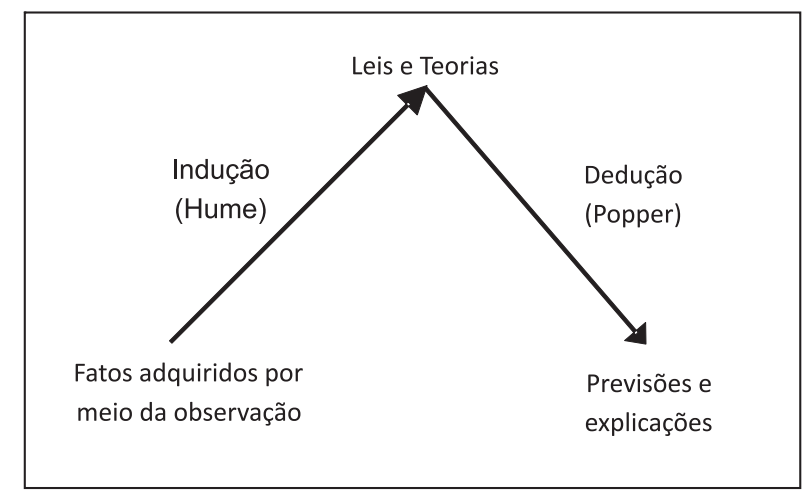

Figura 1: O indutivismo e a dedução

Fonte: Chalmers (1993) 
Cabe salientar que Popper também recebeu críticas, uma vez que uma teoria invalidada empiricamente pode não ser necessariamente inválida. Podem ocorrer problemas nos experimentos, bem como o pesquisador pode não fazer a interpretação adequada dos resultados obtidos. Essa crítica dividiu os seguidores do falseacionismo entre ingênuos e sofisticados.

Trazendo à tona o raciocínio de Popper no sentido de avaliar a cientificidade da administração, utilizando-se esse critério de demarcação científica em particular, entende-se que um número expressivo de pesquisas em administração (excluindo-se os estudos de natureza indutivista) obedece aos critérios estabelecidos por Popper, uma vez que a metodologia estabelecida apregoa: a identificação de um problema; a formulação de hipóteses - método dedutivo; e a corroboração ou a rejeição das hipóteses, ocorrendo, na última possibilidade, o desenvolvimento de novas teorias na administração.

Um dos problemas ocorridos na administração é o atendimento ao critério de falseamento em se tratando do falseacionismo ingênuo. Aparentemente, é notório que teorias em administração não foram falseadas anteriormente, a exemplo da teoria clássica da administração. Os princípios gerais da administração de Fayol, por exemplo, poderiam ser falseados. Fayol contemplava, em seus estudos, que as organizações deveriam ser regidas por quatro princípios básicos: planejamento, organização, direção e controle. Apesar da efetiva contribuição de Fayol, ressalta-se que nem todas as empresas aplicam - a exemplo do desenvolvimento de projetos de novos produtos e serviços em departamentos de Pesquisa e Desenvolvimento de empresas de alta tecnologia - a rígida implementação dos princípios de Fayol, que poderiam inibir a criatividade e a produtividade dessas empresas. No entanto, é importante salientar que, na visão falseacionista sofisticada, os princípios de Fayol não são descartados, mas melhorados, uma vez que não foi apresentada uma que a substitua.

Nesse contexto, sob a ótica do falseacionismo sofisticado, desde que as teorias sejam passíveis de falseamento empírico, podem ser consideradas científicas. Nesse sentido, observa-se que grande parte das teorias da administração atende a esse critério, o que permite considerar, conforme os critérios de demarcação científica de Popper, a administração uma ciência. 


\subsection{A Ciência na Visão de Thomas Kuhn - A Questão dos Paradigmas}

Thomas S. Kunh é reconhecido como um marco na história das ciências e o precursor da noção de paradigma. Físico teórico, ele interessou-se pela Filosofia da Ciência. No período em que atuou como Junior Fellow, na Society of Fellows, da Harvard University, Kuhn utilizou parte de seu tempo para apreciar as questões relativas à história da ciência. A obra intitulada $A$ Estrutura das Revoluções Científicas foi concebida nesse período, sendo o texto originalmente publicado em 1962, sob o título The Structure of Scientific Revolution.

O termo paradigma é oriundo da filosofia. De acordo com Abbagnano (2000), paradigma significa "modelo ou exemplo". Kuhn (2003) o resgatou e o empregou com o significado de "modelo", utilizando-se da Física, da Astronomia, da Química, dentre outras ciências, para ilustrá-lo.

Para esse estudioso da história do progresso das ciências,

[...] paradigmas são as realizações científicas universalmente reconhecidas que, durante algum tempo, oferecem problemas e soluções modelares para uma comunidade de praticantes de uma ciência (KUHN, 2003, p. 17).

Kuhn (2003, p. 23) salienta que "as ciências, em relação ao estágio de desenvolvimento alcançado, podem ser classificadas como normais ou amadurecidas quando possuem um ou vários paradigmas estabelecidos, aceitos e compartilhados". Já o estágio anterior à efetiva posse de um paradigma define uma ciência como "quase-normal" ou "pré-paradigmática". O autor também ressalta que, quando uma área do conhecimento tem seus paradigmas questionados, essa área poderá estar submetida a um processo de revolução científica, no qual um antigo paradigma poderá ser substituído por um novo, não recaindo sobre a questão da incomensurabilidade, região onde se dá um conflito de teorias que concorrem entre si procurando explicar a mesma realidade, não sendo, portanto, redutíveis uma à outra. Uma vez que um paradigma substitui o anterior até então dominante, a ciência, nesse estágio, é classificada como "pós-paradigmática".

Santos (2004) apresenta uma esquematização gráfica (Figura 2) que demonstra os estágios do progresso científico de uma ciência, conforme mo- 
delo desenvolvido por Kuhn, convergindo ao estágio em que se encontra, na visão desse autor, a administração.

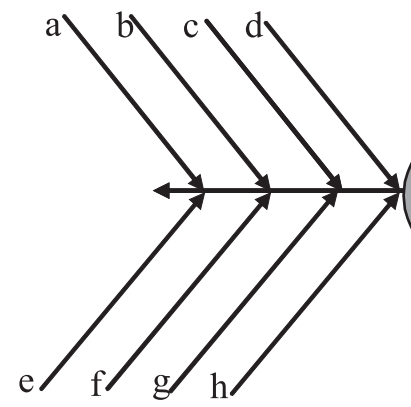

Ciência Quase Normal Estágio Pré-Paradigmático

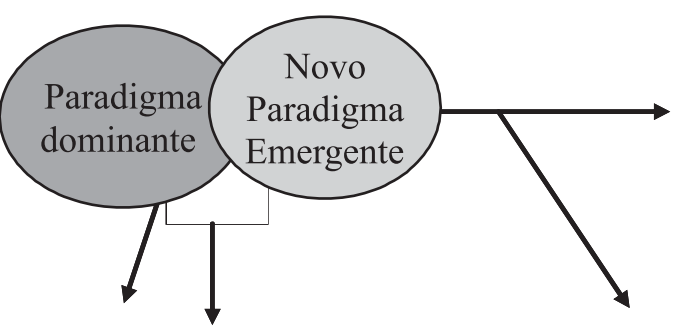

Crise de Paradigma e Estágio de Revolução Científica

\begin{tabular}{|l|l|}
\hline \multicolumn{2}{|l|}{ Legenda: } \\
\hline a: Administração Contingencial & e: Administração Científica \\
\hline b: Administração Estratégica & f: Administração Humanística \\
\hline c: Administração Empreendedora & g: Administração Burocrática \\
\hline d: Outras abordagens & h: Administração Sistêmica \\
\hline
\end{tabular}

Figura 2: Estágios do progresso científico da ciência da administração Fonte: Santos (2004)

Na visão de uma ampla gama de pesquisadores, possuir um paradigma passou a ser um pré-requisito de maturidade para qualquer ciência. Nas ciências sociais, em particular na administração, esse critério tem ampla relevância e é fruto de discussões, uma vez que a dúvida principal relaciona-se sobre qual o estágio atingido por essa ciência.

O entendimento acerca da existência ou não de paradigmas em administração é controverso entre os pesquisadores nesse campo científico. Um dos pontos a ser salientado é a questão "temporal" da administração. Os estudos organizacionais são relativamente recentes, tendo completado pouco mais de 100 anos. Outro ponto importante, e que gera posições divergentes, trata de avaliar o estágio atual da administração quanto à posse ou não de paradigmas estabelecidos.

Basicamente, na visão de Santos (2004), existem dois grupos que avaliam o estágio científico da administração. O primeiro entende que a administração já possui paradigmas estabelecidos e, por conseguinte, argumenta 
que essa ciência se encontra no estágio de ciência normal. Esse grupo exemplifica os paradigmas da administração por meio dos arranjos físicos das fábricas que implementam as linhas de produção, propostos por Taylor, e da implementação dos princípios gerais da administração (planejamento, organização, direção e controle) recomendados por Fayol. Esse grupo de estudiosos e praticantes da administração assume que tais paradigmas da administração orientaram as práticas de organização e gestão da produção nas indústrias, em especial da automobilística, que, posteriormente, foram implementadas em vários setores da indústria manufatureira.

Já Burrell e Morgan (1979) apresentaram quatro paradigmas que norteiam os estudos das ciências sociais, em especial, os estudos das teorias organizacionais: humanismo radical, estruturalismo radical, sociologia interpretativa e sociologia funcionalista. O humanismo radical é representado pelo existencialismo francês, pelo anarquismo e pela teoria crítica; a sociologia interpretativa por Weber e seus seguidores; o estruturalismo radical por Marx e alguns de seus seguidores; e a sociologia funcionalista pelo positivismo. Nos paradigmas defendidos por Burrell e Morgan (1979) repousam grande parte das correntes teóricas da administração.

Quanto ao segundo grupo que avalia o estágio científico da administração, os seus pesquisadores assumem posição contrária ao uso do conceito de paradigma para entender o progresso dessa ciência. Esse grupo enfatiza que a administração encontra-se no estágio de ciência "quase-normal" ou "pré-paradigmática", já que ainda não possui paradigmas aceitos e compartilhados universalmente pela comunidade. Essa visão alinha-se ao posicionamento de Kuhn, uma vez que o autor salienta que as áreas do conhecimento que disputam a condição de se tornar paradigmas em determinada ciência encontram-se no período pré-paradigmático.

Entendendo-se que esse é o estágio em que se encontra a administração, já que ainda não possui paradigmas aceitos e compartilhados universalmente por seus pesquisadores, talvez o paradigma mais próximo de ser aceito universalmente pela comunidade acadêmica seja o paradigma da "eficiência e eficácia". No entanto, ainda não existe consenso de natureza epistemológica e convergência suficiente para assumir tal paradigma.

Para defender o posicionamento de que a administração está na fase pré-paradigmática, Santos (2004) cita algumas Escolas da Administração Administração Científica, Relações Humanas, Burocrática, Sistêmica, Contingencial, por Objetivos, Estratégica, Empreendedora, dentre outras -, 
como escolas teóricas que disputaram em algum momento, ou ainda disputam, tornar-se o paradigma dominante nesse campo científico.

Em síntese, com base nos critérios de demarcação de Kuhn sobre a ciência, aponta-se que a administração pode ser considerada ciência, apesar de não existir consenso sobre o estágio do processo científico no qual ela se encontra: pré-paradigmático - visto que, diante de seu recente surgimento, essa ciência ainda não pôde consolidar seu paradigma - ou ciência normal ao considerar que a estrutura e a dinâmica das diferentes organizações possuem características e uma base comum.

\subsection{A Ciência para Imre Lakatos - Os Programas de Pesquisa}

O húngaro Imre Lakatos é considerado o filósofo que buscou aproximar a filosofia da ciência e a história da ciência em suas investigações. A epistemologia de Lakatos sistematizou de forma importante as características da ciência discutidas até o momento, introduzindo a noção dos "programas de pesquisa".

Para melhor compreensão do significado e aplicação do modelo de Lakatos (1979), recorremos a Chalmers (1993, p. 76), segundo o qual "um programa de pesquisa lakatosiano é uma estrutura que fornece um guia para futuras pesquisas, tanto de maneira positiva, como negativa". Como descrito por Chalmers (1993), os programas de pesquisas de Lakatos (1979) são compostos de heurística negativa, que suporta teorias amplamente aceitas por pesquisadores de um programa de investigação em particular. Esses programas, amparados por um núcleo rígido, são irredutíveis. Por uma decisão metodológica, o núcleo rígido é não refutável, sendo que possíveis discrepâncias em termos de resultados empíricos são eliminadas pela modificação das hipóteses do chamado "cinturão protetor". Essa regra tem como objetivo limitar as falseações. A heurística negativa pode ser considerada uma regra de tolerância que tem por finalidade dar uma chance para que os princípios fundamentais do núcleo apresentem sua potencialidade. Cabe destacar que as teorias do núcleo rígido não são questionadas pelos pesquisadores, característica que se assemelha aos paradigmas de Kuhn (2003).

Na Figura 3, ilustra-se o cinturão protetor que tem por finalidade proteger, com seu núcleo rígido/irredutível, o programa de falseamento. 


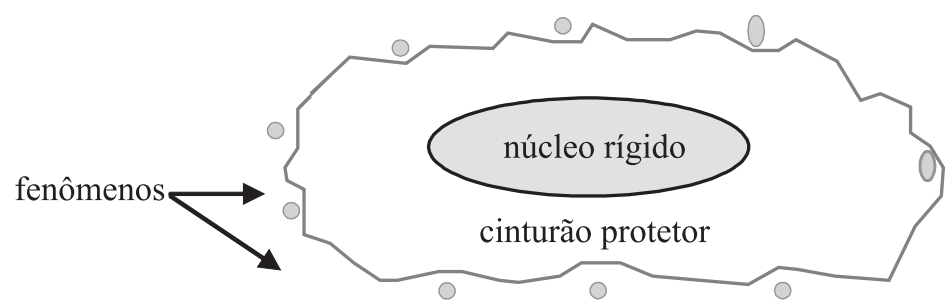

Figura 3: Representação de um programa de pesquisa lakatosiano Fonte: Chibeni (2004)

É importante apontar que Lakatos (1979) reconhece que quando um programa como um todo é incapaz de dar conta de novos e importantes fatos, ele torna-se "degenerante", devendo, possivelmente, ceder lugar a outro programa. Essa é a variável que caracteriza o que o autor denomina heurística positiva de um programa. A heurística positiva, segundo Lakatos (1979, p. 64), consiste "em um conjunto parcialmente articulado de sugestões ou ideias de como mudar ou desenvolver as variantes refutáveis do programa de pesquisa, de como modificar, sofisticar o cinturão protetor refutável". Observa-se que esse elemento da proposta de Lakatos se assemelha às características da corrente falseacionista.

A heurística positiva é composta por respostas provenientes de teorias que residem no núcleo rígido de um programa. Tais hipóteses podem ser falseadas a qualquer momento e substituídas por outras, que atendem com mais propriedade aos problemas que um programa de investigação em particular. De acordo com Lakatos (1979), um programa de investigação entra em declínio quando sua heurística positiva não consegue mais atender aos diversos problemas que se apresentam na evolução da ciência. É o momento em que a heurística negativa é afetada e o programa de investigação pode ser abandonado e, assim, ser substituído por outro, com um núcleo de maior propriedade de maneira a responder com mais efetividade aos problemas identificados no processo de evolução da ciência, característica similar ao que Kuhn define como "crise" e, por conseguinte, o momento das revoluções científicas.

Relacionando as posições de Lakatos (1979) com a administração, é possível tecer algumas considerações, como a característica peculiar da área, que é a excessiva fragmentação (ALBACH; BLOCH, 2000; LOPES; BERNARDES, 2001). Essa condição é fruto de inúmeras críticas, como mencionado anteriormente. Dentre elas, encontra-se, por exemplo, a crítica de 
Burrel (1999), para quem a teoria da organização não teria espaço na academia por ser demasiada fragmentada, uma vez que seu explanans (leis, teoria explicativas ou condições teóricas iniciais) é deficiente e o explanandum (comprovação/corroboração do explanans) é móvel.

A condição de fragmentação talvez seja uma das grandes dificuldades em lidar com "tipos ideais" nos estudos organizacionais, sendo que essa dificuldade explica, em parte, a fragmentação nestes estudos. Contudo, sendo intrínseca a fragmentação da área, causada pela extrema dificuldade de desenvolver produções científicas sustentadas por abordagens "puras" e/ou por tipos ideais - o que traz à tona novamente a discussão da ausência de um paradigma amplamente aceito pela comunidade - pode-se dizer que essa fragmentação consiste em um fator limitador de enquadramento desta área do conhecimento? Acredita-se que não.

Essa concepção de que a fragmentação não consiste em uma limitação da administração decorre do fato de que essa é uma área do conhecimento que lida com fenômenos sociais que fazem parte do contexto administrativo e que estão em constante mutação, destacando-se a incerteza, que decorre, principalmente, de variáveis econômicas macroambientais, e os movimentos competitivos. Isso torna compreensível admitir que a administração seja fragmentada por natureza e por necessidade de abarcar os problemas que a envolvem, o que justifica a seleção de novas maneiras de gerenciar esses fenômenos. O entendimento de Stokes (2007) converge para essa noção ao ressaltar que, atualmente, o mundo turbulento, fragmentado e interconectado exige, das ciências sociais, habilidade e especialização em todos os níveis: individual, local (organizações sociais) e em âmbito amplo (sociedades-estado), bem como instrumentos e metodologias que permitam maior compreensão desse ambiente dinâmico.

A fragmentação nos estudos organizacionais, como observado, é inerente a essa área do conhecimento e novas abordagens são diariamente testadas nas pesquisas no âmbito acadêmico. É preciso reconhecer a dificuldade que existe acerca dessa característica, assim como adotar critérios de demarcação coerentes para a efetiva consistência dos estudos nas áreas organizacionais.

Com base nos moldes dos programas de pesquisa de Lakatos (1979), pode-se considerar a administração uma ciência, uma vez que é justamente esse modelo que permite abarcar a fragmentação desses estudos em uma série de programas de investigação e/ou programas de pesquisa. Grande parte 
das críticas que a administração recebe é tecida justamente em referência à sua natureza multicientífica e multidisciplinar. Considerando-se algumas das principais áreas de estudos da administração (Finanças, Recursos Humanos, Produção, Marketing e Estratégia), por exemplo, torna-se difícil imaginar a administração sem a convergência das áreas dos campos econômico, sociológico e psicológico.

Uma vez as áreas da administração convergindo aos chamados programas de pesquisa lakatosianos, é possível compreender que a administração possui suas áreas e que elas participam de programas de pesquisa com seus núcleos rígidos e irredutíveis e com hipóteses auxiliares passíveis de falsificação. Observando a administração sob essa ótica, é possível legitimá-la como ciência tomando-se por base os moldes lakatosianos.

\section{Considerações Finais}

Neste estudo epistemológico, que objetivou debater a cientificidade da administração, verificou-se que, considerando critérios de demarcação espistemológica, é possível considerar a administração uma atividade científica. Isso porque se observa que estudos dessa área são passíveis de falseamento empírico, conforme o falseacionismo sofisticado de Popper; que a administração atende aos pressupostos da ciência paradigmática de Kuhn, apesar de não existir consenso sobre em que etapa se encontra; e que se adéqua aos moldes dos programas de pesquisa apresentados por Lakatos.

Apesar do exposto, nota-se que parte da academia questiona a cientificidade da administração, o que pode ser explicado pela existência de múltiplos paradigmas e teorias. Assim, essa questão da fragmentação da administração dificulta a efetiva consolidação do status científico dessa área, já atribuído a outras áreas das Ciências Sociais. Contudo, como apresentado neste estudo, isso pode ser explicado por meio da estratégia dos programas de pesquisa explorada por Lakatos.

Além disso, a característica multidisciplinar e multifacetada que leva os estudos organizacionais à fragmentação não pode ser considerada fator determinante para descaracterizar a Ciência da Administração, visto que se observa que, sendo a administração uma área do conhecimento que trabalha com variáveis sociais em constante mutação, é compreensível admitir que essa ciência é fragmentada por natureza e por necessidade de abarcar os 
fenômenos que a envolvem, justificando a seleção de novas maneiras de gerenciar tais variáveis.

No mesmo sentido referido, outra questão que tem levado parte da academia a questionar a administração e sua atividade como ciência são os modismos que dão forma a ela. Talvez essa característica possa ser explicada pela própria evolução dos cenários cujas organizações se inserem: ambientes incertos e em constante mutação conduzem a atividade administrativa a se adaptar constantemente, exigindo novas abordagens e modelos que suportem tais mudanças.

No contexto apresentado, observa-se que a administração ainda possui um longo caminho a percorrer em busca da ampliação de seu rigor metodológico e de seu amadurecimento. No entanto, desconsiderá-la como ciência, além de não auxiliar na consolidação desse processo, acaba por desprestigiar um amplo grupo de atores sociais que não pode ser estudado por outras ciências: as organizações. Dessa forma, mesmo a administração se utilizando de conhecimentos desenvolvidos em outras ciências, possui suas características, pesquisadas apenas no contexto da gestão. Estudos relacionados à contribuição do campo estratégico na sustentabilidade e em desempenhos superiores, os arranjos produtivos, dos tempos e movimentos na atividade industrial, os impactos da atividade humana nas atividades organizacionais e outros são intrínsecos a essa área de conhecimento.

Assim, mais do que em assuntos empíricos e subjetivos, a administração pauta-se nos estudos organizacionais, nas relações com a riqueza, com o ser humano e com os ambientes nos quais a empresa atua. Avaliando sob essa ótica, é visível compreender que, se de um lado, existe um ambiente dotado de pessoas que necessitam de produtos e serviços, de outro, uma entidade que atenda a esses anseios, existe uma área em particular que deve se preocupar em estudar tal relação, que entendemos ser o seu objeto: o estudo da organização e suas relações com o mercado e pessoas. Nesse contexto, todas as organizações necessitam de apoio de uma inteligência diretiva que, atualmente, se pode denominar de administrativa, face ao seu valor científico e social.

Considerando o valor dessa ciência, torna-se importante incitar, nos meios acadêmicos, os debates de natureza epistemológica, assim como a responsabilidade que a comunidade acadêmica deve ter no sentido da construção de conhecimento lógico e racional, rejeitando o relativismo radical, intencionando, dessa forma, a construção de leis gerais ou, no mínimo, a 
busca por predições relativamente concretas e acertadas no sentido de desenvolver e consolidar a administração como ciência.

Para pesquisas futuras, sugere-se ampliar o escopo da discussão por meio de entrevistas a pesquisadores da área de Administração, bem como de outras áreas para analisar os posicionamentos desses indivíduos sobre o tema e as vertentes teóricas nas quais se embasam.

\section{Is Management a Science? Epistemological Considerations about its Scientificity}

\section{Abstract}

This epistemological study aims to expose and discuss the issue of management scientificity. This discussion has been held in other studies, without being, however, like this study, conducted through an epistemological criteria analysis of the philosophers Karl Popper, Thomas Kuhn and Imre Lakatos. On the basis of epistemological analysis, can be concluded: that management, as a theory of knowledge, can be considered science, which arises from the possibility of distorting the studies in this area as sophisticated falsification of Popper, that management meets the assumption science paradigm of Kuhn, although there was no consensus on what stage fits the mold research programs presented by Lakatos. It is known that management still has a long way to go in quest to expand its methodological rigor and mature, but dismissing it as a science, and does not help with the ripening, it undercuts a wide range of social actors - organizations - which are not the main object of study of other sciences.

Key words: Epistemology. Management Scientificity. Karl Popper. Thomas Kuhn. Imre Lakatos.

\section{Referências}

ABBAGNANO, N. Dicionário de filosofia. 4. ed. São Paulo: Martins Fontes, 2000.

ALBACH, Horst. La Economia de La Empresa como Ciencia. Alcalá: Universidad de Alcalá, 1993. 
ALBACH, H.; BLOCH, B. Management as a Science: emerging trends in economic and management theory. Journal of Management History, v. 6, n. 3, 138-15, 2000.

AUGUSTO, Paulo O. M; WALTER, Silvana A. O status científico da pesquisa em administração. Revista de Negócios, v. 13, n. 4 p. 56-71, out./dez. 2008.

BACHELARD, Gaston. A epistemologia. Lisboa: Edições 70, 1971.

BOMBASSARO, Luís Carlos. As fronteiras da epistemologia: como se produz conhecimento. Petrópolis: Vozes, 1994.

BURREL, Gibson; MORGAN, Gareth. Sociological paradigms and organizational analysis. London: Heinemann, 1979.

BURREL, Gibson. Ciência normal, paradigmas, metáforas, discursos e genealogia da análise. In: CLEGG, Stewart R.; HARDY, Cynthia; NORD, Walter R. Handbook de estudos organizacionais. São Paulo: Atlas, 1999. v. 1, p. $439-462$.

CHALMERS, A. F. O que é ciência, afinal? São Paulo: Brasiliense, 1993.

CHIBENI, Silvio S. O que é ciência? Instituto de Filosofia e Ciências Humanas da Unicamp. 2004. Disponível em: <www.unicamp.br/ chibeni>. Acesso em: 12 maio 2008.

CORBI, Mariano. Qué es y para qué sirve la metodologia, 1998. (nãopublicado).

FIGUEIRAS, Eugenio R. Metodologia de las ciências sociales, 1996. (não-publicado).

HOUAISS, Antonio. Dicionário eletrônico Houaiss da língua portuguesa. Rio de Janeiro: Editora Objetiva, 2001 [CD-ROM].

KANT, Emmanuel. Crítica da razão pura. Rio de Janeiro: Tecnoprint, 1971.

KUHN, Thomas S. A Estrutura das Revoluções Científicas. 7. ed. São Paulo: Perspectiva, 2003.

MARIGUELA, Márcio. Epistemologia da psicologia. Piracicaba: Unimep, 1995. 
MACHLUP, Fritz. Are the social sciences really inferior? In: MARTIN, Michael; McINTYRE Lee C. Readings in the Philosophy of Social Science. Cambridge: The MIT Press, 1994, p. 5-20.

LAKATOS, Inre; MUSGRAVE, Alan. A crítica e o desenvolvimento do conhecimento. São Paulo: Editora da Universidade de São Paulo, 1979.

LOPES, Humberto E. G; BERNARDES, Patrícia. Ampliando a análise da produção científica em administração: o indutivo versus o dedutivo. Economia \& gestão, Belo Horizonte, v. 1, n. 2, p. 92-107, jul./dez. 2001.

POPPER, K. R. The Logic of Scientific Discovery. 5. ed. London: Hitchison, 1968.

. Conhecimento objetivo: uma abordagem evolucionária. Editora da Universidade de São Paulo: São Paulo, 1975.

SANTOS, Silvio A. Existem paradigmas em administração? Uma análise sobre o uso do conceito. 2004. Disponível em: <www.fgusp.br/ iberoamerican/Papers/0256>. Acesso em: 12 maio 2008.

SILVA, Eduardo D. Por que la administración de empresas es una ciencia? In: CONGRESSO LATINO-AMERICANO DE ESCOLAS DE ADMINISTRAÇÃO, 37, 2002, Porto Alegre. Anais..., Porto Alegre: Universidade Federal do Rio Grande do Sul, 2002.

STOKES, P. A. The project of scientificisation of sociology and the new sciences of communication. Department of Social Theory \& Institutions, University College Cork, 1985.

THOMPSON, James D. On building an administrative science.

Administrative Science Quarterly, v. 1, n. 1, p. 102-111, 1956.

WHITLEY, Richard. sociology of scientific work and the history of scientific developments. In: BLUME, Stuart S. (ed.). Perspectives in the sociology of science, John Wiley and Sons, Chichester-New York-Brisbane-Toronto, p. 2150, 1977.

ZILLES, Urbano. Teoria do Conhecimento. Porto Alegre: EDIPUCRS, 1994. 